\title{
Learner-Centredness in Teachers'Beliefs: A Qualitative Multiple-Case Study of Chinese Secondary Teachers of English as a Foreign \\ Language
}

\author{
Mingkun Lou ${ }^{1} \&$ Greg Restall ${ }^{1}$ \\ ${ }^{1}$ School of Education, University of South Australia, Adelaide, South Australia \\ Correspondence: Mingkun Lou, School of Education, University of South Australia, Adelaide, South Australia.
}

Received: September 22, 2020

Accepted: October 26, 2020

Online Published: October 27, 2020

doi: $10.5539 /$ elt.v13n11p113

URL: https://doi.org/10.5539/elt.v13n11p113

\begin{abstract}
China's National English Curriculum Standard, launched in 2001, clearly reflects a philosophy and characteristics of learner-centeredness. However, limited evidence is available as to how far the learner-centred philosophy has, through interacting with the local contexts, influenced teachers' beliefs, which will translate into a core philosophy and culture affecting teacher behaviours and practices at the school and classroom levels. Drawing on semi-structured interview data of a larger project, this study reports on three secondary school teachers' overall educational beliefs regarding English teaching, the alignment of their beliefs with learner-centredness and factors influencing their beliefs. The analysis uncovers a wide range of English-teaching related beliefs that positions the three teachers variously on a learner-centred continuum. It also unveils the possible factors that influence teacher beliefs and mediate teachers' application of beliefs. Factors influencing teachers' beliefs range from schooling to significant others. Teachers' reflectiveness is identified as an important influence of teachers' beliefs and uptake of the curriculum reform. Teachers' perceptions and responses to a range of contextual factors mediate the application of their beliefs. This study sheds light on the current status of curriculum reform and the uptake of the learner-centred philosophy by teachers.
\end{abstract}

Keywords: learner-centeredness, English as a foreign or second language, teacher beliefs, teacher reported practices, curriculum reform

\section{Introduction}

The last two decades have witnessed 'a global wave' of large-scale educational reform as influenced by globalization (Yin, 2013, p. 336). As part of the wave, China also launched a radical systematic curriculum reform in 2001 (Ryan, 2011). Grounded in a learner-centred philosophy, the reform aimed to shift the exam-oriented, knowledge-transmissive and teacher-predominant curriculum to a learner-centred, ability-focused and knowledge-construction one, focusing on learners' all-round development and their needs as life-long learners (Carney, 2008, Wang, 2011; Wang \& Ma, 2009, Zhang \& Liu, 2013). Accordingly, China's National English Curriculum Standards emphasize teaching for the overall development of the learner, aiming to facilitate the development of students' English linguistic and communicative competence, learning and thinking ability, intercultural awareness and understanding, and to prepare students for life-long learning and development (MOE, 2001; 2011).

The implementation of curriculum reform has proved challenging in international contexts as it entails the encounter of its underpinning value and philosophy with the traditional culture, values and norms of the school and society at large, the contextual reality and constraints, and the beliefs espoused by individual classroom practitioners (Bantwini, 2010; Barcelos \& Kalaja, 2011; Canh \& Barnard, 2009; Prapaisit de Segovia \& Hardison, 2009; Troudi \& Alwan, 2010). In China, the implementation of the National English Curriculum is also faced with enormous challenges, including the clash of learner-centred padagogy with Chinese traditional pedagogical beliefs, norms, and teacher-dominated teaching styles, which favour rote-learning, pattern drilling, and learning about the language (Fang \& Warschauer, 2004; Hu, 2005), and the traditional perception about good teachers and students as projected by the entrenched exam-oriented educational system (Dello-Iacovo, 2009; Li \& Baldauf, 2011; Liu \& Wu, 2006). These challenges are compounded with other problems, including limited resources and available support involving large class sizes with students of varying English learning 
backgrounds, insufficient and unequal professional preparation or training opportunities, and thus, insufficient understanding of the reform and its underpinning philosophy (Dello-Iacovo, 2009; Fang \& Garland, 2014; Yu, 2003; Zheng, 2013; Zheng \& Borg, 2014). Consequently, there lacks a shared meaning by the teachers about the reform, making it unlikely to trigger belief change, which, as remarked by Fullan (2007), is 'the foundation of achieving lasting change' (p. 37).

Teachers' basic beliefs and assumptions about education, learners, learning and teaching, whether explicit or implicit, will translate into a core philosophy and culture affecting their behaviours and practices at the school and classroom levels (McCombs \& Whisler, 1997). Nevertheless, changes in beliefs are the most difficult aspects of reform as they 'challenge the core values held by individuals regarding the purposes of education' (Fullan, 2007, p. 37). The degree of enactment of the curriculum lies in the degree each individual's belief system is influenced and changed towards a greater alignment of the underpinning philosophy. Little research regarding China's curriculum reform (eg. Zhang \& Liu, 2013; Zheng, 2013) has probed into teachers' perceptions, listening to teachers' voices, or looking at things from teachers' points of view, despite the central and critical role of teachers in shaping classroom reality and in the curriculum implementation process (Datnow, 2020; Yan \& He, 2012; Yuan, 2017). Limited evidence is available as to how far the learner-centred philosophy has, through interacting with the local contexts, influenced teachers' beliefs. Such evidence would be valuable in informing future policy making and professional development programs. This study, therefore, provides an in-depth understanding of three Chinese secondary English teachers' overall educational beliefs regarding EFL teaching, drawing on some data of a larger study investigating EFL teachers' beliefs and practices in non-elite secondary schools in the Southwest of China. This study focuses on the two research questions:

1) How do teachers' EFL-teaching-related educational beliefs align with learner-centredness?

2) What factors influence teachers' EFL-teaching-related educational beliefs?

Taking a qualitative approach, this study gives voice to teachers to report, reflect and theorize on their practices, unveiling factors influencing their beliefs. It provides an up-to-date understanding of the meaning of learner-centredness in relation to second or foreign language (L2) education, offering a foundation for further research dialogue around topics related to learner-centred education, L2 teacher beliefs, curriculum implementation and L2 teacher professional development. It also sheds light on the current status of curriculum reform and the uptake of the learner-centred philosophy by teachers. To provide a frame of reference for the analysis of teachers' beliefs, Section 2 reviews literature about learner-centredness in general education and in L2 education. This is followed by methodological considerations (Section 3) and then the presentation of the research findings (Section 4). Next, it discusses the findings (Section 5) followed by the conclusion of this study.

\section{Literature Review}

\subsection{Learner-Centredness in General Education}

The learner-centred philosophy has guided educational reform and teaching practices in many countries and regions such as the US, China, Thailand, India, North Cyprus, South Africa and European countries (e.g. Altinyelken, 2011; Brinkmann, 2014; Hoidn, 2016; O'Sullivan, 2004; Wang, 2007). However, its meaning has been difficult to conceptualize due to different interpretations and some misunderstandings, and therefore, causes confusion (Schweisfurth, 2013; 2015). Therefore, an up-to-date understanding of its meaning is necessary in order to better inform educational practices and research.

Dating back to child-centred education over 250 years ago, 'learner-centred education' is a term with expanded meaning to apply to learners of all ages, combining 'learner-centred' and 'learning-centred' perspectives. The contemporary meaning of learner-centredness is defined by McCombs and Whisler (1997, p. 9) as having a combined focus on:

- Individual learners - their heredity, experiences, perspectives, backgrounds, talents, interests, capacities and needs

- Learning - the best available knowledge about learning and how it occurs

- Teaching practices - the most effective practices in promoting the highest levels of motivation, learning, and achievement for all learners.

The contemporary meaning of learner-centredness is well-grounded in humanism, which emphasizes the development of the whole person and the importance of the inner world of the learner rather than focusing solely upon cognitive skills (William \& Burden, 1997). To humanists, people are 'free and unique, self-directed, and capable of setting goals, making choices and initiating action'; therefore, parents and teachers should accompany children on the ways to self-discovery, encouraging children's independence, creativity, self-reliance, and 
self-evaluation, as well as giving them responsibility for their own learning and development (McInerney \& McInerney, 2010, pp. 446-447). According to Rogers (1969), one of the founders of humanistic psychology, 'significant learning' occurs when the learner perceives what is to be learned as relevant and when external criticism and perceived threat to the learner's self-image is minimal (pp. 157-159). The learner's 'independence, creativity, and self-reliance are all facilitated when self-criticism and self-evaluation' are encouraged (ibid. p. 163). 'The facilitation of significant learning rests upon certain attitudinal qualities in the personal relationship between the facilitator and the learner' (ibid. p. 104).

Learner-centred teaching focuses attention on what and how the student is learning under what learning conditions, 'whether the student is retaining and applying the learning', as well as 'how current learning positions the student for future learning' (Weimer, 2002, XVI). To adopt learner-centred teaching as proposed by Weimer $(2002 ; 2012)$, the following five areas of change are to be made by teachers:

1. change in the balance of power - teachers willingly and responsibly begin to give students some control over decision making to create motivated, confident and responsible learners;

2. change in the function of content - teachers provide content that has a dual function as a body of knowledge and as a vehicle to develop learning skills;

3. change in the role of the teacher - teachers create climates for learning, do more design work and modelling, do more to encourage students to learn from and with each other, do more with feedback, but do fewer learning tasks and less telling, so that students can do more discovering;

4. change in the responsibility for learning - teachers encourage students to accept the responsibility for learning by creating classroom climates conducive to learning and by building students' autonomy and responsibility;

5. change in the purposes and processes of evaluation - teachers use evaluation experiences to promote learning by focusing on learning processes, reducing the stress and anxiety of evaluation experiences, incorporating more formative feedback mechanisms, using various approaches to assessment, and supporting students in the preparation for assessment.

Based on this review, learner-centredness is defined as the ways in which the teacher tailors all teaching practices to focus on the learning and overall development of the learners, attending to learners' specific affective, cognitive, individual and social needs. These practices include curriculum choices such as sharing power and decision making with learners, being partners with learners in the learning process, engaging learners in active learning and participation, making learning relevant, interesting, challenging and meaningful to learners, maximizing and enabling the dual functions of the resources and materials, and using assessment to facilitate learning.

\subsection{Learner-Centeredness in L2 Education}

The L2 teaching community started to take interest in learner-centered teaching in the $1960 \mathrm{~s}$, with an increasing desire to make teaching more responsive to learners' needs, allowing learners to 'play a fuller, more active and participatory role' in learning (Tudor, 1996, p. 1). Over the years, learner-centredness has had different interpretations associated with a variety of methods or approaches of language teaching, including:

- Communicative language teaching - featuring 'a high degree of peer-to-peer and/or peer-to-teacher interaction', 'authentic, meaningful and purposeful language', involving 'learning how to use' rather than mainly learning about the language, and emphasizing 'meaning over form' (Freeman, 2011; Brown, 2014)

- Task-based language teaching - emphasizing 'classroom interaction', 'authenticity', 'viewing the learner's own experiences as important contributors to learning' (Brown, 2014, p. 237; Ellis, 2003)

- Project-based learning - featuring 'extended tasks' similar to real-life tasks, involving 'integrated language skills', goal-directed group collaboration and discussion, problem solving, oral and written reporting (Hedge, 2002, p. 362; see also Li, 2010; Stoller, 1997).

Learner-centredness is also associated with a range of language learning activities such as group-work activities (Bailey, 2004), information-gap and jig-saw tasks (Shehadeh, 2012).

Nevertheless, learner-centredness is a guiding philosophy that goes beyond methods or activities. It is 'a broadly-based endeavour' that tailors all aspects of language teaching according to learner needs and characteristics (Tudor, 1996, p. ix). In terms of curriculum development, Nunan's (1988) concept of learner-centred curriculum is the most influential, which not only emphasizes the central role of learners as the 
reference point for teachers' decision-making, but more importantly, highlights the active role of learners and the importance of consultation and negotiation with the learners throughout the learning and teaching process. At the classroom level, learner-centredness refers to learners being the centre of the class, actively involved in the learning process, taking charge of their own learning processes, making decisions and plans and doing all the work, while teachers maximize opportunities for learning and interaction (Nunan, 1999; 2004). In terms of learner training, learner-centredness is an educational endeavour which seeks to empower learners by enabling them to assume an informed and self-directive role in the pursuance of their language-related life goals (Tudor, 1996). Therefore, teachers should 'systematically sensitize learners to the learning process and encourage them to gradually take greater responsibility' and move 'toward the fully autonomous end of the pedagogical continuum' with the support of appropriately developed curricula and materials (Nunan, 1988, p. 12).

To sum up, based on the review so far, from a learner-centred perspective,

- the aims of $\mathbf{L 2}$ teaching are to facilitate the overall development of learners, to develop learners' thinking and learning ability to be self-regulated life-long learners and social beings, and to develop students' overall language proficiency and competence, intercultural awareness and communicative competence;

- in learners, teacher and learner-teacher relationships, the learners are positioned as unique individuals with different capacities, characteristics, preferences and backgrounds, but everyone is capable of learning and taking responsibilities. Teachers are not authority figures, but normal people equal in relationship to the students. The teacher and students are partners and co-creators of the learning experience with the attitudinal qualities of the teacher being a key factor influencing learning;

- for learning and teaching, learning is facilitated in a safe environment with minimal external criticisms and perceived threats to learners' self-image, and teachers accept and appreciate learners for who they are, valuing their perspectives and catering for individual differences and needs, giving learners freedom of choice and responsibility for learning. Learning is also facilitated by meaningful social interaction and is more effective when it is goal-oriented, relevant and interesting to learners, engaging learners in active meaning-making and participation;

- for content, textbooks and resources, content should have a dual function as a body of knowledge and as a medium to develop learning skills; textbooks and resources should be adapted to be developmentally appropriate, meaningful and relevant to students; and a wide variety of input and resources should be used to enrich and facilitate learning;

- for assessment, diverse forms of assessment and choices should be provided and learner input incorporated; additionally, assessment experiences should be used to promote learning by focusing on learning processes.

As a widely-embraced endeavour in the language teaching community (e.g. Bao, 2013; Haley, 2004; Hanifehzadeh \& Ebrahimi, 2015; Lee \& Chen, 2010), the learner-centered classroom promotes effective teaching and learning, which is particularly true of L2 learning, as a learner-centered classroom minimizes learners' anxiety, facilitates learners' willingness to communicate and motivation to learn, and maximizes classroom interaction and practicing opportunities, which are all crucial factors that influence the rate and success of L2 learning (Brown, 2014; Cohen, 2011; Dörnyei, 1998; Kang, 2005; MacIntyre et al., 1998; Peng, 2012).

\section{Method}

This study forms part of a study investigating Chinese EFL teachers' beliefs and practices involving seven teachers in two non-elite secondary schools in a Southwestern city in China. A purposive sampling procedure was used to select research sites (non-elite secondary school) and a 'maximal variation principle' was used within the selected research sites to sample teachers who differ in some characteristics such as age and teaching experience (Bryman, 2012, pp. 418-419; see also Creswell, 2013). To provide a detailed presentation of teachers' beliefs and factors influencing their beliefs, this paper focuses on the presentation of data about three teachers, who were selected due to the fact that they each embrace EFL-related teaching beliefs that sit them variously along a learner-centred continuum. The basic information about the participants, Anli, Fang, and Guiyun (pseudonyms), is summarized in Table 1. 
Table 1. Basic information about the participants

\begin{tabular}{llll}
\hline Participant & Anli & Guiyun & Fang \\
\hline Age & $35-40$ & $50-55$ & $45-50$ \\
Highest Degree & Bachelor of Arts in TESOL & $\begin{array}{l}\text { Bachelor of Arts in } \\
\text { English Literature }\end{array}$ & $\begin{array}{l}\text { Bachelor of Arts in } \\
\text { English Literature }\end{array}$ \\
Year Level & 8 & 9 & 8 \\
Class size & 56 & 37 & 45
\end{tabular}

The data that this paper draws on was generated from an interview of approximately two hours with each participant. These qualitative interviews consisted of open-ended questions to obtain detailed information about the teachers' 'thoughts, beliefs, knowledge, reasoning, motivations and feelings' about topics relevant to EFL teaching (Johnson \& Christensen, 2012, p. 202). An interview protocol (see Appendix 1) was used, mainly drawing upon the teacher beliefs survey and teacher classroom practice survey developed by Mid-continent Regional Educational Laboratory (McREL, cited in McCombs \& Whisler, 1997).

The interviews were conducted in Mandarin and audio-recordings of the interviews were transcribed by a contracted transcriptionist, verified and then selectively translated when quoted in this study by the researcher. All the data was organized into files in Nvivo 10 and then, as a starting point to code the data, five a priori categories based on the literature review were used, namely beliefs about:

- Goals of English education

- Learners, teacher and learner-teacher relationships

- $\quad$ Learning and teaching

- Content, textbooks and resources

- Assessment

Using the five categories of beliefs as a tool, one teacher's interview data was examined, coded first with Nvivo 10 and then by hand a few times, while any comments, thoughts, concerns were marked down, noting down the emerging themes within each category of beliefs. Along with the emerging themes, the factors influencing teacher beliefs were also coded. This process was applied to the other teachers' interview data, while common patterns and themes were identified, and variations or comparisons across the participants were noted. In the end, 23 themes about teacher beliefs emerged and 6 themes about the influencing factors were identified.

\section{Results}

This section begins with a detailed presentation of teachers' educational beliefs regarding EFL teaching in order to answer the first research question 'How do teachers' educational beliefs related to EFL teaching align with learner-centredness?' This is followed by the presentation of the factors influencing teachers' beliefs.

\subsection{Teachers'Educational Beliefs Regarding EFL Teaching}

Of the 23 themes about teacher beliefs, some were shared by all three teachers, while others were embraced only by one of them. A belief may have been fully supported by one teacher while only partly supported by others.

\subsubsection{Beliefs about Aims of L2 Teaching}

Three aims of teaching were identified: to prepare students for exams, to develop students' ability to speak and use English, and to facilitate students' learning and thinking abilities and overall development. Fang only focused on the immediate instrumental needs of the learners to pass exams, explaining that, 'The exam system is here; you will have to take the exams.' Guiyun prioritized the aim of developing students' ability to speak and use English, although she felt she 'had no choice but to teach mainly according to the exams' and therefore 'focused more on written exercises and grammar rules in teaching. She wished to 'experience the way of teaching advocated by the textbook', which was 'up-to-date and practical, aiming to develop students' ability to speak and use English'. Anli accommodated all three aims in her teaching, aiming to attend to learners' immediate instrumental needs of passing exams and their broader and longer-term needs, such as their ability to speak and use English, and ability to learn, think and survive in future society. Anli believed that:

English is a language, so students should listen more and speak more ... Its function should be the

focus ... what is learned should be used, regardless whether listening, speaking or writing (Anli). 
Anli also reported purposefully incorporating the demonstration of learning strategies and ways of thinking, 'asks students to share' learning strategies and ways of thinking and facilitate learners' self-reflection on 'where the problem lay' and on the effectiveness of their ways of learning. She aimed to facilitate the overall development of each student as a person, which she considered the ultimate goal of education, believing that 'in the long run, I am teaching students how to be a person rather than teaching English only'.

\subsubsection{Beliefs about Learners, the Teacher and Learner-Teacher Relationships}

The three teachers' views converged regarding learner differences and teachers' presenting their real selves. They believed that teachers should cater for individual differences and support each learner to achieve progress; teachers were role models exerting great impact on students (Anli, Guiyun); teachers' attitudes and feelings influenced students' greatly (Guiyun, Fang); learners should be appreciated for who they are (Anli); and 'hard work counts more than natural endowment' (Guiyun).

However, their views diverged regarding teacher authority and the attribution of failure. Fang seemed to have a negative profile of the learners and attributed some students' inability to learn well due to individual differences:

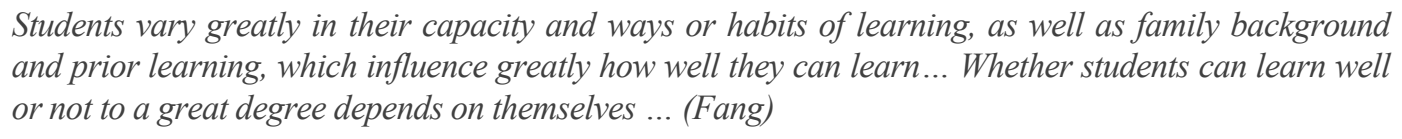

Students vary greatly in their capacity and ways or habits of learning, as well as family background and prior learning, which influence greatly how well they can learn... Whether students can learn well or not to a great degree depends on themselves ... (Fang)

She maintained that if students were not learning or were causing problems, the problem must lie more with the students than with the teacher. In addition, Fang maintained that 'teachers should be strict and serious in class when necessary ... [as] ... if teachers are more serious and fiercer, there would be fewer discipline problems in the classes'

By contrast, Anli and Guiyun both thought that teachers were normal people equal in relationship to students and they preferred to present their real selves to the students. Rather than taking an authoritative stance, Anli and Guiyun maintained that good interpersonal relationships with students was the key to successful teaching and such relationships could be achieved through open communication with students. Otherwise, as Anli reflected on her observation of her mentors and other colleagues, 'no matter how hard-working a teacher is, the teaching effect will not be good'. Guiyun reported never having any scolding attitudes towards students, as 'students may close their hearts simply because of a careless word from the teacher'. Furthermore, they both maintained that when things go wrong, teachers should reflect on their own practice first, which is also contradicting to Fang's view.

\subsubsection{Beliefs about Learning and Teaching}

Teachers' commonly held that learning is facilitated in a caring, respectful, trustful learning environment where individual differences are catered for and participation is encouraged. Besides the common belief, Fang believed in creating 'a relaxing atmosphere in classes' and Guiyun pointed out the importance of attending to students' 'physical and mental' wellbeing. In terms of effective learning or significant learning, Guiyun regarded the following qualities as important: appropriate level of difficulty, group work and peer teaching, and learner self-initiation and active participation. However, she did not mention learners taking responsibilities.

Like Fang and Guiyun, Anli embraced the qualities for a facilitating learning environment. She also believed that gradually giving learners more responsibility for learning facilitates learning, regarding the following qualities as important to facilitate effective or significant learning: relevance and interest, an appropriate level of difficulty, learner self-initiation and active participation, and group work and peer teaching.

\subsubsection{Beliefs about Content and Resources}

Overall, the participants had a consensus view that textbooks and other resources should be used flexibly and adapted to suit students' pace and needs. However, their beliefs diverged regarding whether covering the content is less important than teaching to students' real understanding and developing students' abilities. Fang believed that it is necessary to selectively use textbooks and resources, adjusting when necessary. However, she prioritized covering the content and keeping up with the pace with no concerns. Guiyun also reported mainly focusing on covering all the content despite there being too much to cover. She also reported using the supporting resources and teaching aids as they were, commenting 'not unnecessary, but no time nor energy to adapt it'.

In contrast, Anli strongly believed that teaching to students' real understanding and ability development is more important than covering the content and that it is necessary to selectively use textbooks and resources, adjusting when necessary. She thought that 'the textbook was not quite suitable for the students of her province', so, rather 
than teaching to the book, page by page, she filtered it and synthesized it to teach students skills and develop their abilities. If there was a 'critical teaching moment', she would 'seize it and make good use of it to emphasize something important'.

\subsubsection{Beliefs about Assessment}

All the three teachers held the beliefs that assessment should be used both of and for learning and that the teacher should systematically monitor students' progress to provide feedback on individual progress and to adjust teaching accordingly. Fang reported using exams to monitor students' progress to provide feedback, but mainly focusing on diagnosing 'what [linguistic] aspects need to be emphasized' to re-emphasize them in teaching. Besides 'systematically monitoring students' progress, Guiyun reported using exam results to facilitate reflection: for students to reflect on their own 'learning effectiveness' and on what they 'haven't done well enough', and for teachers to reflect on 'what needs improving in their own teaching'.

Similar to Guiyun, Anli believed that teachers should systematically monitor students' progress to give encouragement as appropriate to different students in different aspects and adjust teaching accordingly. However, using formative assessment regarding subject-content areas and giving learners some control regarding assessment was only identified in Anli's data. Anli reported using an everyday class report as formative assessment of students' oral English ability, even though not required by the school. This activity allows some freedom of choice according to individual preference and style. Students are required to take turns to do an oral presentation as an assessment task at the beginning of the first lesson each day. They can decide on the when, what and how to do it, whether to do it individually or in groups and whether to tell stories, present a dialogue, or whatever forms they prefer. Furthermore, making use of exams to motivate students in active learning and thinking is inferred only in Anli's data. She reported asking students to explain and demonstrate understanding of the questions that they have done incorrectly in the exams in order to increase their grades by 'earning points back' with hard work.

In summary, the analysis uncovers a wide range of teacher beliefs related to EFL teaching, which position the three teachers variously on the learner-centred continuum, with Anli to a great extent and Fang to a little extent aligning with learner-centredness, while Guiyun lies in between. Aligning to a great extent with learner-centredness, Anli:

- embraced the aims of facilitating learners' ability to speak and use English, and to facilitate their thinking, learning and overall abilities, rather than only to pass exams

- believed that learning is facilitated in a positive and safe learning environment, where learners' individual differences are catered for, learners are respected, valued and accepted for who they are

- $\quad$ believed that deep learning takes place when learning is made relevant, interesting and meaningful to learners and when learners are engaged in active learning, thinking, discussion and participation

- thought that content and resources should be adapted flexibly as appropriate to students' developmental level and learning needs, and that teaching to students' real understanding and developing students' ability to learn and to think is more important than covering the content

- maintained that assessment should be used for learning rather than on learning only, and teachers should monitor students' progress constantly to provide feedback on individual growth and to teach accordingly; expressed a view of incorporating the learner in assessment.

Sitting on the other end of the continuum, Fang maintained that the textbooks and resources should be used flexibly and adapted to facilitate learning, assessment should be of learning and for learning, and teachers should constantly monitor students' progress so as to adjust teaching accordingly, but her only aim of teaching is to prepare students for exams. Fang acknowledged the importance of catering for learners' individual differences and the importance of fostering a relaxed classroom climate in facilitating learning, but she held a pessimistic view about the future learning outcomes of students who had poor prior learning. Although she preferred to show her real self to the students and treat them equally as friends with understandings, she regarded teacher authority as a means of reducing discipline problems.

Lying in between Anli and Fang, Guiyun embraced two aims, which she considered contradictory to each other: 'exams' and 'students' ability to speak and use English'. She embraced similar beliefs to Anli's regarding 'learning and teaching' and 'learners, teacher and the learner-teacher relationship', except for learners taking responsibilities and relevance of learning. Regarding assessment, she reported systematically monitoring students' progress and using exam results to facilitate student and teacher reflection. However, giving learner control, choice or incorporating learner input were not identified. Regarding contents and resources, she reported 
mainly focusing on covering the content, although she expressed her concerns about how to cover the important points for exam purposes and at the same time keep the students interested and teaching in the way advocated by the up-dated textbooks. She also reported using the supporting resources and teaching aids as they were due to time constraints.

\subsection{Factors Influencing Teacher Beliefs}

A wide range of factors were identified as influencing teacher beliefs, including teachers' individual background and experiences; collegial influence or anti-apprenticeship experience/notions; influence of significant others; PD recommendations and contextual factors. Teachers' beliefs about different aspects were also found to influence their beliefs about other aspects.

\subsubsection{Teachers' Individual Background and Experiences}

Teachers' individual backgrounds and experiences were found to have had a great impact on their beliefs, namely, their own schooling experience, experience as an English learner and user and their own teaching experience. For example, Anli embraced the aim of facilitating students' ability to speak and use English rather than only focusing on grammar rules due to her reflections on her experience as a language learner in which grammar knowledge was the focus of teaching. Despite having a good command of grammar knowledge, she used to be not sufficiently confident to communicate with English native speakers. For another example, Guiyun's belief regarding 'incorporat[ing] more listening and speaking activities can lead to better exam results was influenced by her teaching experience that language learning was more effective if teachers facilitate studentsistening to use the language rather than only to rote learn the words and grammar.

As EFL learners and users themselves share similar backgrounds, teachers embraced the qualities for a facilitating learning environment, as influenced by their empathy with the students as learners of a foreign language:

\section{It is likely that the students dislike learning English and dare not open their mouths to speak if teachers are too serious and harsh, as it is very hard for students to learn a foreign language, which is remote and strange to them, with so many new words and content (Anli).}

\subsubsection{Collegial Influence or Anti-Apprenticeship Experience/Notions}

Collegial influence or anti-apprenticeship experience/notions influence teacher beliefs. For example, Anli's belief that teachers should not be authority figures in front of students was influenced by her observation of her mentor as a novice teacher, saying that even though her mentor was experienced:

He was too authoritative and far away from the students, so the students obeyed him out of fear or coercion. That's why the good effect didn't last long (Anli).

She did not want to be like her mentor, so she had this anti-apprenticeship observation belief.

Anli's belief that good interpersonal relationships with students was the key to successful teaching was influenced by her observation of other teachers' practices. She then believes that:

... in order to increase the grades of the whole class, besides working hard, another important factor is to win the children's hearts ... once you have won their hearts, they will be happy to follow you and do whatever you want them to do or accept your words or comments from their hearts (Anli).

\subsubsection{Influence of Significant Others}

Teachers' beliefs were influenced by significant others. For example, Anli's belief regarding the obligatory use of exams to motivate students in active learning and thinking was influenced by a Chinese scholar named Zou Hong, who dealt with his daughter's mistakes in exam papers in a similar way. Her belief regarding gradually giving learners more responsibility for learning to facilitate learning was greatly influenced by her father, who was her middle school mathematics teacher. Her father called upon her to replace him as teacher when he had to attend a conference. She was not confident at first, but her father encouraged her and asked her to think first and then tell him how she would teach her classmates. Then her father gave her some feedback on how to improve. She said that she would never forget how to deduce the median line of a trapezoid and she would remember that lesson all her lifetime.

\subsubsection{Professional Development Recommendations}

Teachers beliefs were influenced by professional development (PD) recommendations. For example, Anli's beliefs about qualities such as relevance, interest and learners' active participation as important to facilitate 
effective or significant learning was also influenced by the 2001 Curriculum Standards reinforced in different PDs, which she found resonant with what she really espoused, commenting that:

\section{Learner-centred teaching has been reinforced again and again in different trainings and programs. I have been constantly thinking about it ..., making an effort to let students do the telling and explaining more (Anli).}

However, PD programs and recommendations do not always make an impact on teachers. For example, despite having had opportunities to attend a range of PD programs and to witness some alternative teaching practices which seemed effective and interesting, Fang had rarely changed.

... teaching in a more learner-centred way was mentioned earlier in PD programs, but I rarely thought about how to use it and didn't really put it into practice ... there are some activities in the teaching reference book which I sometimes adopt, but not often (Fang).

\subsubsection{Contextual Factors}

Contextual factors that were identified to have influenced teachers' beliefs include the perceived importance of exams for students, the written and grammar-focused nature of exams, the nature of the textbooks, time constraints, students' low English level; observation of the common phenomenon of English learners in China. For example, perceiving the exams as 'the baton', Fang only embraced the aim of 'preparing students for exams'. She saw that 'the students were highly active in some classes' that she observed. However, she 'didn't apply the activities' in her own class due to the reason that she 'always felt the activities would take a lot of time'. Fang reported giving extra support to students who were slow in learning but limited to those students that she felt would possibly catch up due to the large class size. Guiyun 'emphasized what is likely to appear in exams', and 'there is no time for expansion ... [given the] huge amount of content in the textbook [and] ... the generally poor English foundation of the students' and also because 'teaching and learning is mainly judged based on the exam results'.

Anli believed that textbooks and teaching aids should be selectively used, adapted flexibly to suit the students' pace and needs due to her consideration of time constraints and exams. She stated that:

\section{I have to filter the activities; some I may not ask students to do ... Time does not allow. Even the simple} two-minute activities may take 20 minutes in practice (Anli).

Anli thought such time could be 'better used', and the new textbooks made her reflect more deeply about their effective use. She thought teachers should be more 'flexible in class, caring more about students' reactions and real understanding and learning', rather than 'following the lesson plans and pace strictly' to cover the planned content.

\section{Discussion}

Based on the analysis, four points will be discussed. First of all, the uptake of the curriculum reform in China. Previous studies in China mainly suggest that 'the spirit of the 2001 National Curriculum Standards for secondary schools has not really been put into effect and that the EFL teachers' elementary goals of preparing students for various public exams and their role as knowledge-givers or transmitters through grammar-translation have remained unchanged (e.g. Li, 2019; Li \& Baldauf, 2011; Wang \& Zhao, 2010; Yan \& He, 2012). Nevertheless, the findings in this study suggest that change is taking place to varying degrees for different teachers as evident in the three teachers' beliefs and reported practices. The three teachers represent three categories of teachers in the process of curriculum reform: namely, the autonomous teachers who embrace educational beliefs and practices highly aligned with the beliefs underpinning the reform; the non-changers who still reside in the zone of traditional beliefs and practices comfortably without questioning their beliefs and how effective their practices are, on whom the reform has had minimal impact yet; and teachers in the changing process, desiring for a change in practice yet finding themselves facing dilemmas.

The second point relates to teachers' sharing of some common beliefs, probably due to similar background such as being Chinese L2 learners of English and the larger sociocultural influence. For example, the commonly held belief that learners are unique individuals with varied characteristics, backgrounds and prior learning, and these should be catered for in teaching may have been influenced by the Confucius educational principle of yin cai shi jiao, literally meaning to teach a person based on his or her ability (Low, 2010), or to tailor teaching to cater for individual differences. For another example, with their experience as an English learner and user, the teachers generally expressed empathy with the students as learners of English as a foreign language and therefore wished to create a learning environment that was conducive to learning. This 'empathy' of non-native English-speaking teachers resonates with findings in other research studies (e.g. Ma, 2012). Such empathy, as 
Kramsch (2004) points out, is required of the language teachers who 'have to remember what it felt like to learn a new language, the linguistic and culture shocks experienced, the challenges and rewards encountered along the way' (p. 255).

The third point is that teachers' perceptions and response to the contextual factors mediate the application of their beliefs. With their unique individual backgrounds, the teachers' perceptions and responses to the contextual factors vary greatly, and thus they reported acting differently. For example, textbooks and time constraints were responded to differently by Anli and Guilin, which suggests that it is teachers' perceptions about the contextual factors that forms a mediating influence on teachers' application of their beliefs. For another example, Fang resided in the traditional way of practice, socialized or conditioned to ways of thinking and doing things, accepting the norms and common practice of teaching according to exams. She perceived contextual constraints such as the large class size and the large number of slow students as overwhelming, which she used to theorize her reported practice, such as selectively supporting students who were likely to catch up and her practice of 'teaching to the middle'. She seemed to have regarded this approach as a norm without questioning the viability of her own practice and exploring alternative ways. Teachers were to some degree conditioned to certain practices. This finding can be well explained by Crookes (2015) comment that:

\section{Ideas of mainstream culture, often pervasive, allow most people few alternative ways of thinking about any phenomenon or issue (and thus inhibit active forms of social action or change to improve conditions) (p. 490).}

Thus, this finding helps to explain why some teachers remained traditional or were slow in change. Given that teachers are conditioned to a certain way of teaching, it is deemed challenging to change their beliefs and practices. Thus, change is not likely to take place unless deemed imperative.

Guiyun emphasized her doubt and questions about the traditional ways of teaching, while feeling vulnerable in making a change, therefore suffering from not being able to teach as she wishes. By contrast, Anli was more assertive, explaining that teachers should try their best to cater for individual differences despite it being 'hard', and she seemed to have more control over how to use the textbooks to facilitate learning. Being the only teacher to use formative assessment on the subject content area to monitor and promote the development of students' English-speaking ability, she went beyond what is required by the school, indicating the high degree of 'flexibility' she perceived to occupy her 'perceived curriculum decision-making operational space', and make decisions for which she is responsible (Smith, 1983, p. 29). The findings point to the needs for more professional support to build up teachers' capacity and expand their perceived curriculum decision-making operational space (Fullan, 2007; Smith, 1983).

This mediation process of teachers' perception provides an explanation for the incongruence between teachers' beliefs and practices that has been well identified and discussed by other researchers (e.g. Phipps \& Borg, 2009; Shah, Othman \& Senom, 2017; Zeng, 2012; Zheng, 2013). While previous studies have identified similar contextual factors (e.g. Farrell \& Bennis, 2013; Li, 2013, Nishino, 2012) and commonly identified and discussed in research studies about China's curriculum reform and implementation (e.g. Li \& Baldauf, 2011; Yan \& He, 2012; Zheng, 2013), the findings of this study highlight the concept of teachers' perception about these factors. Teachers varied in their response to similar contextual factors, as influenced by their initial conditions, which play a vital role in 'shaping' teachers' 'current practices and sense-making processes' (Kubanyiova, 2012, p. 192).

The fourth and last point arising from this study is that teachers' reflectiveness influences their belief change and uptake of curriculum reform. The findings show that teachers' reflectiveness on their own learning and teaching experience and on how their own practice projects the students for the future also makes a difference. For example, Anli's beliefs about effective learning of English was influenced by her critical reflection on her own experience as a language learner and user and on the common phenomenon of English learners in China. For another example, giving learners some control is only reported by Anli, which she believed to be effective in facilitating active learning. This belief, as generated from her practice, was initially influenced by her observation of other teachers' classes when she was a novice teacher. However, it was her reflectiveness, adaptiveness as well as her beliefs about effective learning and teaching that made her adapt her students' activity to an assessment task, involving all the class to give feedback to and grade the presenters. This shows that reflection on one's own or others' teaching and/or learning experiences and practices, traditional practices and norms may lead teachers to try out alternative practices and/or to a change in their belief system, which resonates with the findings of other studies (e.g. Breen et al., 2001; Farrell \& Ives, 2015). This finding has pointed to the importance of teachers' reflectiveness, which is 'of considerable value as a process of 
consciousness raising and enhancing understanding' (Walsh, 2006, p. 127). Given the importance of teachers' reflection and the fact that not all language teachers are aware of their beliefs or to what extent their beliefs are reflected in their classroom practices, teachers' reflection should be a focus of teachers' professional development.

\section{Conclusion}

This study has provided an in-depth understanding of three Chinese secondary school teachers' overall educational beliefs regarding EFL teaching and factors influencing their beliefs. The analysis has uncovered a wide range of beliefs related to EFL teaching that positions the three teachers variously on a learner-centred continuum, which shows China's learner-centred curriculum reform is taking effect to various degrees as evident in the three teachers' beliefs and reported practices. A wide range of factors are identified as influencing teacher beliefs and mediating teachers' application of beliefs. While teachers' share some common beliefs possibly due to their similar background such as being Chinese L2 learners of English and the larger sociocultural influence, their reflectiveness is identified as a major influence of their beliefs and uptake of curriculum reform. The application of teachers' beliefs is mediated by teachers' perceptions of a range of contextual factors.

This study involves three teachers in a secondary school in a city in the Southwest of China only. Therefore, interpreting findings should be done with reference to the contextual information provided. The data were generated through co-construction by the researcher and the participants and it only represents the three teachers' beliefs at the moment when the data were gathered. The findings in this study could hardly represent the mass of Chinese Secondary EFL teachers due to the significant economic, social and educational differences across different regions in China. Despite the limitations associated with the research findings, this study offers a foundation for further research dialogue around topics related to learner-centred education, L2 teacher beliefs, curriculum implementation and L2 teacher professional development.

The overall landscape of a teacher's beliefs might be indicative of their practice. However, it is possible that teachers may believe in one thing and do another as has been well identified and discussed by other researchers (e.g. Basturkmen, Loewen \& Ellis, 2004; Farrell \& Lim, 2005; Phipps \& Borg, 2009; Shah, Othman \& Senom, 2017; Zeng, 2012; Zheng, 2013). Therefore, to fully understand teachers and teaching, as well as the complex relationships between their beliefs and practices, an understanding of teachers' actual practices and their theorization of their practices is essential.

\section{List of Abbreviations}

$\begin{array}{ll}\text { EFL } & \text { English as a foreign language } \\ \text { L2 } & \text { Foreign or second language } \\ \text { PD } & \text { Professional development } \\ \text { TESOL } & \text { Teaching English to speakers of other languages }\end{array}$

\section{Acknowledgements}

The authors would like to thank Emeritus Professor Dr. Bruce, Johnson, Dr. Monica Behrend, Dr. Jenny Barnett and members of the TESOL Researchers Group at the University of South Australia for their constructive comments and feedback in helping to shape the paper.

\section{Ethics Approval and Consent to Participate}

This research was granted ethics approval by the Human Research Ethics Committee of the University of South Australia (Application ID: 0000032852). Signed informed consent forms were obtained from the school authority and the participants.

\section{Competing Interests}

No competing interests.

\section{Declarations}

This paper is based on Mingkun Lou's Ph.D Thesis.

\section{Funding}

This research was supported by the Commonwealth Government funding of Australia for Research Training Program (RTP). 


\section{References}

Altinyelken, H. K. (2011). Student-centred pedagogy in Turkey: Conceptualisations, interpretations and practices. Journal of Education Policy, 26(2), 137-160. https://doi.org/10.1080/02680939.2010.504886

Bailey, K. M. (2004). Speaking. In Nunan, D. (Ed.), Practical English language teaching. Higher Education Press, Beijing.

Bantwini, B. D. (2010). How teachers perceive the new curriculum reform: Lessons from a school district in the Eastern Cape Province, South Africa. International Journal of Educational Development, 30(1), 83-90. https://doi.org/10.1016/j.ijedudev.2009.06.002

Bao, F. (2013). The application of learning styles in learner-centered EFL teaching in China. In Hung, J. K. \& Fan, R. (Eds.), Proceedings of the Sixth International Symposium: Education innovation and Dunhuang culture engineering, Dunhuang, China (pp. 162-166). https://doi.org/10.5503/J.PR.2013.13.016

Barcelos, A. M. F., \& Kalaja, P. (2011). Introduction to beliefs about SLA revisited. System, 39, 281-289. https://doi.org/10.1016/j.system.2011.07.001

Basturkmen, H., Loewen, S., \& Ellis, R. (2004). Teachers' stated beliefs about incidental focus on form and their classroom practices. Applied Linguistics, 25, 243-272. https://doi.org/10.1093/applin/25.2.243

Breen, M. P., Hird, B., Milton, M., Oliver, R., \& Thwaite, A. (2001). Making sense of language teaching: Teachers' principles and classroom practices. Applied Linguistics, 22(4), 470-501. https://doi.org/10.1093/applin/22.4.470

Brinkmann, S. (2015). Learner-centred education reforms in India: The missing piece of teachers' beliefs. Policy Futures in Education, 13(3), 342-359. https://doi.org/10.1177/1478210315569038

Brown, H. D. (2014). Principles of language learning and teaching: A course in second language acquisition. White Plains, NY: Pearson Education.

Bryman, A. (2012). Social research methods. Oxford: Oxford University Press.

Canh, L. V., \& Barnard, B. D. (2009). Curricular innovation behind closed classroom doors: A Vietnam case study. Prospect, 24(2), 2033.

Carney, S. (2008). Learner-centred pedagogy in Tibet: international education reform in a local context. Comparative Education, 44(1), 39-55. https://doi.org/ 10.1080/03050060701809417

Cohen, A. D. (1998). Strategies in learning and using a second language. Harlow: Longman.

Cohen, I. (2011). Teacher-student interaction in classrooms of students with specific learning disabilities learning English as a foreign language. Journal of Interactional Research in Communication Disorders, 2(2), 271-292. https://doi.org/10.1558/jircd.v2i2.271

Creswell, J. W. (2013). Qualitative inquiry and research design: choosing among five approaches (3rd ed.). Thousand Oaks: Sage Publications.

Datnow, A. (2020). The role of teachers in educational reform: A 20-year perspective. Journal of Educational Change, 21, 431-441. https://doi.org/10.1007/s10833-020-09372-5

Dello-Iacovo, B. (2009). Curriculum reform and 'quality education' in China: An overview. International Journal of Educational Development, 29(3), 241-249. https://doi.org/10.1016/j.ijedudev.2008.02.008

Dörnyei, Z. (1998). Motivation in second and foreign language learning. Language teaching, 31(3), 117-135. https://doi.org/10.1017/s026144480001315x

Ellis, R. (2003). Task-based language learning and teaching. Oxford: Oxford University Press.

Fang, X., \& Garland, P. (2014). Teacher Orientations to ELT Curriculum Reform: An Ethnographic Study in a Chinese Secondary School. The Asia-Pacific Education Researcher, 23(2), 311-319. https://doi.org/10.1007/s40299-013-0106-9

Fang, X., \& Warschauer, M. (2004). Technology and Curricular Reform in China: A Case Study. TESOL Quarterly, 38(2), 301-323. https://doi.org/ 10.2307/3588382

Farrell, T. S. C., \& Bennis, K. (2013). Reflecting on ESL teacher beliefs and classroom practices: a case study. RELC Journal, 44(2), 163-176. https://doi.org/10.1177/0033688213488463

Farrell, T. S. C., \& Ives, J. (2015). Exploring teacher beliefs and classroom practices through reflective practice: A case study. Language Teaching Research, 19(5), 594-610. https://doi.org/10.1177/1362168814541722

Farrell, T. S. C., \& Lim, P. C. (2005). Conceptions of grammar teaching: a case study of teachers' beliefs and classroom practices. TESL-EJ, 9(2), 1-13. 
Freeman, D. (2011). Complex dynamic systems: A new transdisciplinary theme for applied linguistics? Language Teaching, 45(2), 202-214. https://doi.org/10.1017/s0261444811000061

Fullan, M. (2007). The new meaning of educational change. New York: Teachers College Press.

Gao, X., \& Ma, Q. (2011). Vocabulary learning and teaching beliefs of pre-service and in-service teachers in Hong Kong and mainland China. Language Awareness, 20(4), 327-342. https://doi.org/10.1080/09658416.2011.579977

Gao, Y., Zhao, Y., Cheng, Y., \& Zhou, Y. (2007). Relationship between English learning motivation types and self-identity changes among Chinese students. TESOL Quarterly, 41(1), 133-155. https://doi.org/10.1002/j.1545-7249.2007.tb00043.x

Goh, C. C. M., \& Chen, Z. (2014). Teaching Spoken English in China: The relationship between beliefs and characteristics of university EFL teachers. In Said, S. B., \& Zhang, L. J. (Eds.), Language Teachers and Teaching: Global Perspectives, Local Initiatives (pp. 109-126). New York: Routledge.

$\mathrm{Gu}$, M. (2008). Identity construction and investment transformation: college students from non-urban areas in China. Journal of Asian Pacific Communication, 18(1), 49-70. https://doi.org/10.1075/japc.18.1.04gu

Haley, M. H. (2004). Learner-centered instruction and the theory of multiple intelligences with second language learners. Teachers College Record, 106(1), 163-180. https://doi.org/10.1111/j.1467-9620.2004.00326.x

Hanifehzadeh, S., \& Ebrahimi, S. (2015). Learner-centered approaches of language teaching at the service of language instructors in Hong Kong. Modern Journal of Language Teaching Methods, 5(2), 109-118.

Hedge, T. (2002). Teaching and learning in the language classroom. Shanghai: Shanghai Foreign Language Education Press.

Hoidn, S. (2016). The pedagogical concept of student-centred learning in the context of European higher $\begin{array}{lllll}\text { education reforms. } & \text { European Scientific Journal, 12(28), 439-458. }\end{array}$ https://doi.org/10.19044/esj.2016.v12n28p439

$\mathrm{Hu}, \mathrm{G}$. (2005). English language education in China: policies, progress, and problems. Language Policy, 4(1), 5-24. https://doi.org/10.1007/s10993-004-6561-7

$\mathrm{Hu}, \mathrm{Y}$. (2007). China's foreign language policy on primary English education: What's behind it? Language Policy, 6(3-4), 359-376. https://doi.org/10.1007/s10993-007-9052-9

$\mathrm{Hu}, \mathrm{Y}$. (2008). China's English language policy for primary schools. World Englishes, 27(3-4), 516-534. https://doi.org/10.1111/j.1467-971X.2008.00582.x

Johnson, B., \& Christensen, L. (2012). Educational research: quantitative, qualitative, and mixed approaches, Thousand Oaks, Calif.: Sage Publications.

Kang, S. J. (2005). Dynamic emergence of situational willingness to communicate in a second language. System, 33(2), 277-292. https://doi.org/10.1016/j.system.2004.10.004

Kaufeldt, M. (2010). Begin with the brain: orchestrating the learner-centered classroom. Thousand Oaks: Corwin Press. https://doi.org/10.4135/9781483350448

Kramsch, C. (2004). Language, thought, and culture. The handbook of applied linguistics, 235-261. https://doi.org/10.1002/9780470757000.ch9

Kubanyiova, M. (2012). Teacher development in action: understanding language teachers' conceptual change. Basingstoke: Palgrave.

Lambert, N. M., \& McCombs, B. L. (1998). Introduction: Learner-centered schools and classrooms as a direction for school reform. In Lambert, N. M. \& McCombs, B. L. (Eds.), How students learn: Reforming schools through learner-centered education (pp. 1-22). American Psychological Association. https://doi.org/10.1037/10258-017

Lee, I. Y. N., \& Chen, K. T. (2010). Learner-centered writing: English as a foreign language. International Journal of Learning, 17(6), 231-244. https://doi.org/10.18848/1447-9494/cgp/v17i06/47115

Li, K. (2010). Project-based college English: An approach to teaching non-English majors. Chinese Journal of Applied Linguistics, 33(4), 99-112.

Li, L. (2013). The complexity of language teachers' beliefs and practice: One EFL teacher's theories. Language Learning Journal, 41(2), 175-191. https://doi.org/10.1080/09571736.2013.790132

Li, M., \& Baldauf, R. (2011). Beyond the curriculum: A Chinese example of issues constraining effective English language teaching. TESOL Quarterly, 45(4), 793-803. https://doi.org/10.5054/tq.2011.268058

Low, K. C. P. (2010). Confucius and his learning \& teaching ways. Global Education Journal, (4), 87-104. 
Ma, L. P. F. (2012). Strengths and weaknesses of NESTs and NNESTs: Perceptions of NNESTs in Hong Kong. Linguistics and Education, 23(1), 1-15. http://doi.org/10.1016/j.linged.2011.09.005

MacIntyre, P. D., Clément, R., Dörnyei, Z., \& Noels, K. A. (1998). Conceptualizing willingness to communicate in a L2: A situational model of L2 confidence and affiliation. The Modern Languag Journal, 82(4), 545-562. https://doi.org/10.1111/j.1540-4781.1998.tb05543.x

McCombs, B. L., \& Whisler, J. S. (1997). The learner-centered classroom and school: strategies for increasing student motivation and achievement (1st ed.). San Francisco: Jossey-Bass.

McInerney, D. M., \& McInerney, V. (2010). Educational psychology: constructing learning. Pearson Australia: Frenchs Forest, N.S.W.

Ministry of Education. (2001). Quanrizhi yiwu jiaoyu putong gaoji zhongxue yingyu kecheng biaozhun (shiyangao). [English curriculum standards for full-time compulsory and senior high schools (trial)]. Beijing: Beijing Normal University Press.

Ministry of Education. (2011). yiwu jiaoyu putong gaoji zhongxue yingyu kecheng biaozhun (2011ban) [English curriculum standards for compulsory education (2011 version)]. Beijing: Beijing Normal University Press.

Nishino, T. (2012). Modeling teacher beliefs and practices in context: A multimethods approach. Modern Language Journal, 96(3), 380-399. https://doi.org/10.1111/j.1540-4781.2012.01364.x

Nunan, D. (1988). The learner-centred curriculum: A study in second language teaching: Cambridge University Press. https://doi.org/10.1017/cbo9781139524506

Nunan, D. (1999). Second language teaching \& learning. Boston, Mass.; London: Heinle \& Heinle Publishers.

Nunan, D. (2004). Task-based language teaching. Cambridge: Cambridge University Press. https://doi.org/10.1017/cbo9780511667336

O’Sullivan, M. (2004). The reconceptualisation of learner-centred approaches: A Namibian case study. International Journal of Educational Development, 24(6), 585-602. https://doi.org/10.1016/s0738-0593(03)00018-x

Peng, J. E. (2012). Towards an ecological understanding of willingness to communicate in EFL classrooms in China. System, 40(2), 203-213. https://doi.org/10.1016/j.system.2012.02.002

Phipps, S., \& Borg, S. (2009). Exploring tensions between teachers' grammar teaching beliefs and practices. System: An International Journal of Educational Technology and Applied Linguistics, 37(3), 380-390. https://doi.org/10.1016/j.system.2009.03.002

Prapaisit de Segovia, L., \& Hardison, D. M. (2009). Implementing education reform: EFL teachers' perspectives. ELT Journal, 63(2), 154-162. https://doi.org/10.1093/elt/ccn024

Rogers, C. R. (1969). The increasing involvement of the psychologist in social problems: Some comments, positive and negative. The Journal of Applied Behavioral Science, 5(1), 3-7. https://doi.org/10.1177/002188636900500101

Ryan, J. (2011). Education Reform in China. London: Routledge. https://doi.org/10.4324/9780203816028

Schweisfurth, M (2015). Learner-centred pedagogy: Towards a post-2015 agenda for teaching and learning. International Journal of Educational Development, 40, 259-266, https://doi.org/10.1016/j.ijedudev.2014.10.011

Schweisfurth, M. (2013). Learner-centred Education in International Perspective: Whose pedagogy for whose development? London, New York: Routledge Taylor \& Francis Group. https://doi.org/10.4324/9780203817438

Shah, S. S. A., Othman, J., \& Senom, F. (2017). The pronunciation component in ESL lessons: Teachers' beliefs and practices. Indonesian Journal of Applied Linguistics, 6(2), 193-203. https://doi.org/10.17509/ijal.v6i2.4844

Shehadeh, A. (2012). Learner-centered instruction in the ELT classroom: What, why and how? Perspectives (TESOL Arabia), 19(3), 5-12.

Smith, D. (1983). On the concept of perceived curriculum decision-making space. Curriculum Perspectives, 3(1), 21-30.

Stoller, F. L. (1997). Project work: A means to promote language content. English Teaching Forum, 35(4), 2-9.

Tian, J. (2013). Beliefs and practices regarding intercultural competence among Chinese teachers of English at a Chinese university. Proquest Llc, 14(3), 115-124. 
Tong, F., \& Shi, Q. (2011). Chinese-English bilingual education in China: a case study of college science majors. International Journal of Bilingual Education and Bilingualism, 15(2), 165-182. https://doi.org/10.1080/13670050.2011.607921

Troudi, S., \& Alwan, F. (2010). Teachers' feelings during curriculum change in the United Arab Emirates: Opening Pandora's box. Teacher Development, 14(1), 107-121. https://doi.org/10.1080/13664531003696659

Tudor, I. (1996). Learner-centredness as language education. Cambridge; New York, NY: Cambridge University Press.

Walsh, S. (2006). Investigating classroom discourse: Routledge. https://doi.org/10.4324/9780203015711

Wang, D. (2011). The dilemma of time: student-centered teaching in the rural classroom in China. Teaching and Teacher Education, 27(1), 157-164. http://doi.org/10.1016/j.tate.2010.07.012

Wang, J., \& Zhao, Z. C. (2011). Basic education curriculum reform in rural China. Chinese Education \& Society, 44(6), 36-46. https://doi.org/10.2753/ced1061-1932440603

Wang, Q. (2007). Primary EFL in China: teachers' perceptions and practices with regard to learner-centredness. University of Warwick.

Wang, Q., \& Ma, X. (2009). Educating for learner-centredness in Chinese pre-service teacher education. Innovation in Language Learning and Teaching, 3(3), 239-253. https://doi.org/10.1080/17501220903404475

Weimer, M. (2002). Learner-centered teaching: five key changes to practice. San Francisco: Jossey-Bass.

Weimer, M. (2012). Learner-centered teaching: five key changes to practice (2nd ed.). San Francisco, CA: Wiley Jossey-Bass.

Williams, M., \& Burden, R. L. (1997). Psychology for language teachers: a social constructivist approach, Cambridge University Press, New York.

Woodrow, L. (2011). College English writing affect: self-efficacy and anxiety. System, 39(4), 510-522. http://doi.org/10.1016/j.system.2011.10.017

Yan, C., \& He, C. (2012). Bridging the implementation gap: an ethnographic study of English teachers' implementation of the curriculum reform in China. Ethnography and Education, 7(1), 1-19. https://doi.org/10.1080/17457823.2012.661585

Yang, L., \& Gao, S. (2013). Beliefs and practices of Chinese university teachers in EFL writing instruction. Language, Culture and Curriculum, 26(2), 128-145. https://doi.org/10.1080/07908318.2013.794817

Yin, H. (2013). Implementing the National Curriculum Reform In China: A Review of the Decade. Front Education China, 8, 331-359. https://doi.org/10.1007/BF03396979

Yu, W. S. (2003). Guo jia ji ke cheng gai ge shi yan qu jiao xue gai ge diao yan bao gao [A report of the teaching innovation in the pilot areas of national curriculum reform]. Jiao yu yan jiu [Educational Research], 24(11), 39-43.

Yuan, R. (2017). Appropriating national curriculum standards in classroom teaching: Experiences of novice language teachers in China. International Journal of Educational Research, 83, 55-64. https://doi.org/10.1016/j.ijer.2017.02.011

Zeng, Z. (2012). Convergence or divergence? Chinese novice EFL teachers' beliefs about postmethod and teaching practices. English Language Teaching, 5(10), 64-71. https://doi.org/10.5539/elt.v5n10p64

Zeng, Z., \& Murphy, E. (2007). Tensions in the language learning experiences and beliefs of Chinese teachers of English as a foreign language. TESL-EJ, 10(4), 1-19.

Zhang, F., \& Liu, Y. (2013). A study of secondary school English teachers' beliefs in the context of curriculum reform in China. Language Teaching Research, 18(2), 187-204. https://doi.org/10.1177/1362168813505940

Zhang, X. (2013). Foreign language listening anxiety and listening performance: conceptualizations and causal relationships. System, 4l(1), 164-177. http://doi.org/10.1016/j.system.2013.01.004

Zheng, H. (2013). The dynamic interactive relationship between Chinese secondary school EFL teachers' beliefs and practice. Language Learning Journal, 41(2), 192-204. https://doi.org/10.1080/09571736.2013.790133

Zheng, X., \& Borg, S. (2014). Task-based learning and teaching in China: Secondary school teachers' beliefs and practices. Language Teaching Research, 18(2), 205-221. https://doi.org/10.1177/1362168813505941 


\section{Appendix 1 Interview Protocol}

Date

Interviewee

\section{Basic information of teachers}

Age

Years of teaching

Degree

Major

Focus 1: Lesson plan (discuss the plan for the whole term and for the focused week).

1. When you plan the lesson, what concerns you most? (students' needs, prior learning, interest, learning style, covering contents, teach for the exams, overall development of students, students learning skills and strategies, grammar, listening, speaking, reading, writing ability...?

\section{Focus 2: Textbook and resources}

2. What do you think of the textbook and what is the role of the textbook?

3. What other resources or materials do you use besides the textbook?

\section{Focus 3: Assessment}

4. What exams do students have to sit and what do you think of the exams? (school level, city level ...)

5. Do you think your most important job is to help students pass the exams with good grades?

6. How do you monitor and assess students' progress? Why? (purposes, self-assessment, peer assessment...)

\section{Focus 4: Environment/atmosphere/interpersonal relationship}

7. What is the classroom atmosphere in your class like?

8. What are your relationship with the students and the relationship between students like? (caring, trust, respectful, encouraging, competitive, cooperative, relaxing, stress-free ...)

9. If you feel very bad one day, would you show your true self to the students and share with them your feelings, or would you not let students know about it? Why?

10. Would you prefer to share who you are as a person with your students or to be an authority figure.

11. What would you do and how would you feel if you make a mistake in front of the students?

12. Do you try your best to get to know students personally? (backgrounds, interests, motivation, learning styles, aspiration...)

13. Do you encourage students to express their personal beliefs and feelings? Why?

14. Do you address students' social, emotional, and physical needs? How?

\section{Focus 5: Responsibilities/power relationship}

15. Who set the classroom rules for management and discipline?

16. Who decorates the classroom?

17. Do you give students some choices in decision-making? In what way? (management, class rules, contents, tasks, homework, assessment ...)

\section{Focus 6: How students develop and learn}

18. Do you think students are similar and learn in similar ways?

19. If students are not motivated to learning English, what would you do?

20. Do you treat students in the same way with the same standard?

21. Do you agree that innate ability is fairly fixed and some children just can't learn as well as others? 
22. Are there any students who are just not smart enough, even with feedback or hints, they just can't figure out their mistakes?

23. Are there any students who are so hard to deal with as to let you feel upset and inadequate?

24. Do you think some students are unreachable no matter what you do or how hard you try?

25. What would you do if some students just refused to learn?

26. Do you think it is too late to help some students to learn English?

27. What would you do if some students consistently caused problems in class?

28. What would you do with students who are slow in understanding or not progressing well?

29. Do you think students can get the right answers or make progress without your direct teaching and telling them the answers?

\section{Focus 7: Goals of English Education}

30. What do you think are the goals of English teaching?

- to get good grades in exams

- to speak fluent English

- to be able to pronounce accurately

- to learn about grammar rules and use grammar correctly

- to be able to communicate with others

- to accumulate vocabulary

- to develop interests and a positive attitude towards English and English language learning

- to develop cultural awareness and broaden outlook

- to develop learning skill and strategies

- to develop overall English abilities

- to develop language awareness and learning ability

- to develop students' self-confidence in learning and communicating in English

- to learn to cooperate and interact with others, respect others' ideas and share opinions with others

\section{Focus 8: About the 2001/2012 curriculum reform}

31. What do you know about the 2001/2012 curriculum standards?

32. Have you ever read them?

33. Have you ever received any training about them?

34. What's your understanding of learner-centredness (advocated in the curriculum standards)?

Adapted from teacher beliefs survey, teacher classroom practice survey developed by Mid-continent Regional Educational Laboratory (McCombs \& Whisler 1997).

\section{Copyrights}

Copyright for this article is retained by the author(s), with first publication rights granted to the journal.

This is an open-access article distributed under the terms and conditions of the Creative Commons Attribution license (http://creativecommons.org/licenses/by/4.0/). 